Department of Health and Social Security (1972). Report on Confidential Enquiries into Maternal Deaths in England and Wales, 1967-69, p. 86. London, H.M.S.O.

Geddes, A. M., Munro, J. F., Murdoch, J. McC., Begg, K. J., and Burns, B. A. (1967). In Proceedings of Fifth International Congress of ChemoB. A. (1967). In Proceedings of Fifth International Congress of Che

Gray, J. E., Purmalis, A., and Fienestra, E. S. (1964). Toxicology and Applied Pharmacology, 6, 476.

Kaplan, K., Chew, W. H., and Weinstein, L. (1965). American fournal of Medical Science, 250, 137.

Kislak, J. W. (1972). Fournal of Infectious Diseases, 125, 295. MacAuley, M. A., and Charles, D. (1968). American fournal of Obstetrics and

Medina, H., Fiske, N., Hjelt-Harvey, I., Brown, C. D., and Prigot, A. (1964). Antimicrobial Agents and Chemotherapy, 1963, 3, 189.

Morrow, S., Palmisano, P., and Cassidy, G. (1968). Fournal of Pediatrics, 73, 262.

O'Driscoll, K., Jackson, R. J. A., and Gallagher, J. T. (1969). British Medical fournal, 2, 477.

O'Driscoll, K., Jackson, R. J. A., and Gallagher, J. T. (1970). Fournal of Obstetrics and Gynaecology of the British Commonwealth, 77, 385.
Paterson, L., Henderson, A., Burnett, L. C., and McGurk, S. (1970). Fournal of Obstetrics and Gynaecology of the British Commontwealth, 77, 565.

Pearson, H. E., and Anderson, G. V. (1967). Obstetrics and Gynecology, 30,

Pearson, H. E., and Anderson, G. V. (1970). Obstetrics and Gynecology, 35,

Robinow, M., and Simonelli, F. A. (1965). American Fournal of Diseases of Children, 110, 92

Sakula, A. (1954). British fournal of Tuberculosis, 48, 69.

Speert, H. (1943). American fournal of Obstetrics and Gynecology, 45, 200

Stewart, K. S., Shafi, M., Andrews, J., and Williams, J. D. (1973). To be published.

Straw, R. N., Hook, J. B., Williamson, H. E., and Mitchell, C. L. (1965). Fournal of Pharmaceutical Sciences, 54, 1814.

Tracy, O., Gordon, A. M., Moran, F., Love, W. C., and McKenzie, P. (1972). British Medical fournal, 1, 280

Williams, J. D., and Felton, D. J. C. (1966). Fournal of Obstetrics and Gynaecology of the British Commonwealth, 73, 654

Wolz, J. H. E., and Wiley, M. M. (1946). Fournal of the American Medical Association, 131, 969 .

\title{
Hypertension in Renal Transplant Recipients: Role of Bilateral Nephrectomy
}

Medical Unit, St. Mary's Hospital, London W.2

SIMON L. COHEN, M.B., M.R.C.P., Senior Medical Registrar (Present address: St. Mary's Hospital, Harrow Road, London W.9) recipients. Because of differing durations of follow-up the comparison was made at an arbitrary point six months after transplantation.

\section{Method}

The data for this study were collected by retrospective analysis of the follow-up charts of the kidney transplant recipients. At the six-month point after operation the patients returned to the clinic at monthly intervals, or more frequently if the kidney was functioning poorly. At least three sets of observations and frequently four or five were made for the period of five to seven months after operation. Means of the following parameters were recorded-systolic and diastolic blood pressure, serum creatinine, creatinine clearance, and prednisone dosage in $\mathrm{mg} / \mathrm{kg}$-and they were compared for the nephrectomized and nonnephrectomized patients. In addition the records were checked to see if the patients were receiving antihypertensive medication. In those noted to be hypertensive at six months the charts were analysed to determine the subsequent course of the blood pressure and renal function. For the purposes of this study hypertension was defined either as the presence of a sustained diastolic blood pressure of $100 \mathrm{~mm} \mathrm{Hg}$ or more or the requirement of antihypertensive drugs other than diuretics to control blood pressure.

The patients' records before transplantation were examined to see if they had malignant hypertension as defined by the presence of papilloedema and fundal haemorrhages and exudates, either before starting or during the dialysis period, and to find out if hypertension was a problem during the dialysis period. Details of any drugs required to control hypertension on dialysis were noted. Means of blood pressure recordings taken in the last month preceding transplantation were calculated.

The kidney transplants concerned in this study were performed between 1 January 1966 and 30 September 1971. In that time 147 kidneys were transplanted, of which 81 functioned for six months or more. These 81 are considered in this report. Fifty-nine transplants were grafted to bilaterally nephrectomized recipients and 22 were put into recipients who retained their own diseased kidneys. Only four of the kidneys were from live related donors, the remainder were cadaveric kidneys. 


\section{Results}

At six months after transplantation there was a significant excess of hypertension in the non-nephrectomized patients as compared to the nephrectomized recipients (table I).

TABLE I-Incidence of Hypertension Six Months after Transplantation

\begin{tabular}{|c|c|c|c|c|c|}
\hline & & & & $\begin{array}{l}\text { Nephrectomized } \\
\text { Patients }(\mathrm{n}=59)\end{array}$ & $\begin{array}{l}\text { Non-nephrectomized } \\
\text { Patients }(n=22)\end{array}$ \\
\hline $\begin{array}{l}\text { Normotensive } \\
\text { Hypertensive }\end{array}$ & $\because$ & .. & $\because$ & $\begin{array}{l}35 \\
24\end{array}$ & $\begin{array}{r}5 \\
17\end{array}$ \\
\hline
\end{tabular}

$\chi^{2}=7 \cdot 18 ; 0.001<P<0.01$

The actual levels of blood pressure recorded were compared, though the patients who were hypertensive were usually receiving drug treatment for this, and so the difference in recorded levels has been reduced (table II). Though blood pressure is significantly higher in the non-nephrectomized patients renal

TABLE II-Blood Pressure Levels and Renal Function in Recipients. Figures are Mean \pm S.E. of Mean

\begin{tabular}{l|c|c}
\hline & $\begin{array}{c}\text { Nephrectomized } \\
\text { Patients (n=59) }\end{array}$ & $\begin{array}{c}\text { Non-nephrectomized } \\
\text { Patients (n=22) }\end{array}$ \\
\hline Systolic Blood Pressure (mm Hg) & $137 \cdot 0 \pm 1 \cdot 9$ & $144 \cdot 1 \pm 3 \cdot 3^{*}$ \\
Diastolic Blood Pressure (mm Hg) & $94 \cdot 7 \pm 1 \cdot 3$ & $99.9 \pm 2.2 *$ \\
Creatinine Clearance (ml/min) & $59 \cdot 0 \pm 3.8$ & $80 \cdot 3 \pm 7.3$ \\
Serum Creatinine (mg/100 ml) .. & $1.6 \pm 0.2$ & $1.3 \pm 0.1$ \\
\hline
\end{tabular}

$* 0.01<P<0.05$ derived from Student's $t$ test.

function is also better in them, suggesting that they are hypertensive in spite of good function of the transplant. This is further illustrated by table III which shows that when renal function is

TABLE III-Renal Function in Hypertensive Recipients. Figures are Mean \pm S.E. of Mean

\begin{tabular}{|c|c|c|}
\hline & $\begin{array}{l}\text { Nephrectomized } \\
\text { Patients }(n=24)\end{array}$ & $\begin{array}{l}\text { Non-nephrectomized } \\
\text { Patients }(n=17)\end{array}$ \\
\hline $\begin{array}{l}\text { Creatinine Clearance }(\mathrm{ml} / \mathrm{min}) \ldots \\
\text { Serum Creatinine }(\mathrm{mg} / 100 \mathrm{ml}) \ldots\end{array}$ & $\begin{array}{r}52 \cdot 5 \pm 4 \cdot 8 \\
2 \cdot 2 \pm 0 \cdot 4\end{array}$ & $\begin{aligned} 74 \cdot 6 \pm 7 \cdot 9 * \\
1 \cdot 4 \pm 0 \cdot 2 \dagger\end{aligned}$ \\
\hline
\end{tabular}

$* 0.001<P<0.01$ derived from Student's $t$ test.

$+0.01<P<0.05$.

compared in the two groups of hypertensive patients it is significantly better in the non-nephrectomized group. There is a significant difference in renal function between the normotensive and hypertensive patients in the nephrectomized group, suggesting that hypertension in this group may be related to poor renal function. (Mean creatinine clearance \pm S.E. of mean $81.2 \pm 4.6 \mathrm{ml} / \mathrm{min}$ and serum creatinine $1.1+0.07$ $\mathrm{mg} / 100 \mathrm{ml}$ in the normotensives and creatinine clearance $52.5 \pm 4.8 \mathrm{ml} / \mathrm{min}$ with serum creatinine $2.2 \pm 0.4 \mathrm{mg} / 100 \mathrm{ml}$ in the hypertensives of this group. Both differences are significant, $P<0.001$ by Student's $t$ test.) Though function in the normotensive patients in the group retaining their own kidneys is better than that of the hypertensives, this difference is not significant. It would appear too that renal function in the normotensive non-nephrectomized patients may be better than the renal function of the normotensive nephrectomized group, though these differences are not significant.

There was a similar incidence of hypertension in association with poor renal function, as defined by a creatinine clearance of less than $50 \mathrm{ml} / \mathrm{min}$ and serum creatinine of more than 1.5 $\mathrm{mg} / 100 \mathrm{ml}$ in the two groups, occurring in nine out of 59 nonnephrectomized and five out of 22 nephrectomized recipients. Hypertension was transient-that is, it disappeared later in the course of the transplantation in a similar proportion of nephrectomized and non-nephrectomized patients (eight out of 59 as compared to three out of 22). Transient hypertension in one patient in the non-nephrectomized group was caused by stenosis of the renal artery of the transplant and was abolished by repair of the stenosis. Postoperatively he remained normotensive without drugs and his renal function improved from a creatinine clearance of $70 \mathrm{ml} / \mathrm{min}$ with a serum creatinine of $1.5 \mathrm{mg} / 100 \mathrm{ml}$ to a clearance of around $120 \mathrm{ml} / \mathrm{min}$ with a serum creatinine of $1 \mathrm{mg} / 100 \mathrm{ml}$. There was a significant difference in incidence of persistent hypertension occurring in the presence of continuing good renal function in nine out of 22 of the recipients retaining their own kidneys as compared to four out of 59 of the nephrectomized patients $\left(\chi^{2}=11.4\right.$, $P<0.001)$. Another three nephrectomized recipients were hypertensive at six months with good renal function but subsequently their renal function deteriorated. In these patients the presence of hypertension heralded the decline in renal function.

Hypertension before transplantation was reviewed to see if the nephrectomized and non-nephrectomized patients differed in incidence or severity of hypertension at that stage. The incidence of malignant and dialysis-resistant hypertensionthat is, hypertension which cannot be controlled by ultrafiltration and sodium restriction alone-was similar in the two groups. It must be emphasized that in many patients with malignant hypertension on entering the programme blood pressure is readily controlled by dialysis alone. Conversely, some patients in whom hypertension does not appear to be severe at the time of starting dialysis experience great difficulty in control of blood pressure and appear resistant to dialysis alone. No patients who were normotensive on starting dialysis became hypertensive during their period on dialysis.

The mean blood pressure \pm S.E. of mean of the nephrectomized recipients in the month preceding transplantation was $146.2 \pm 2 \cdot 9 / 94.7 \pm 2.2 \mathrm{~mm} \mathrm{Hg}$, and for the recipients who retained their own kidneys $152.6 \pm 4.0 / 95 \cdot 1 \pm 2.6 \mathrm{~mm} \mathrm{Hg}$. These figures are not significantly different by Student's $t$ test. When comparing the pretransplantation blood pressure with the value at six months the only significant difference was for the fall in systolic pressure in the nephrectomized group.

Of the 17 patients in the nephrectomized group in whom hypertension was a problem in spite of dialysis only four remained hypertensive in the presence of good renal function after transplantation, whereas three of the five dialysis-resistant hypertensives among the non-nephrectomized group subsequently had hypertension with a transplanted kidney functioning well.

It has been suggested that hypertension late in the course of successful renal transplantation may be related to the dose of steroids required for immunosuppression (Starzl et al., 1964). This factor was examined in these patients and there was no significant difference in prednisone dosage between the nephrectomized and non-nephrectomized groups or between the hypertensive or normotensive patients.

Since starting this study, bilateral nephrectomy has been performed on four patients in the non-nephrectomized group in whom large doses of hypotensive agents were required in the post-transplantation period. All four of these patients had had malignant hypertension before starting dialysis and in all of them great difficulty had been experienced in control of hypertension during the dialysis period. As a routine, arteriography of the transplant to exclude renal artery stenosis was performed before the bilateral nephrectomy. Two of these patients had poor renal function at the time of bilateral nephrectomy, and though the amount of drugs required to control hypertension fell transiently in both cases hypertension returned and within six months in one patient renal function had deteriorated so far that the graft was removed. In the other 
TABLB Iv-Effect of Bilateral Nephrectomy after Transplantation on Blood Pressure, Hypotensive Drug Requirements, and Renal Function in Four Originally Non-nephrectomized Recipients

\begin{tabular}{|c|c|c|c|c|c|c|c|c|}
\hline \multirow{3}{*}{$\begin{array}{l}\text { Case } \\
\text { No. }\end{array}$} & \multicolumn{4}{|c|}{ Before Nephrectomy } & \multicolumn{4}{|c|}{ Six Months After Nephrectomy } \\
\hline & \multirow{2}{*}{$\begin{array}{c}\underset{\text { Blood }}{\text { Pressure }} \\
\text { (mm Hg) }\end{array}$} & \multirow{2}{*}{$\begin{array}{c}\text { Hypotensive Drugs } \\
\text { (Requirements per Day) }\end{array}$} & \multicolumn{2}{|c|}{ Renal Function } & \multirow{2}{*}{$\begin{array}{c}\text { Blood } \\
\text { Pressure } \\
(\mathrm{mm} \text { Hg) }\end{array}$} & \multirow{2}{*}{$\begin{array}{c}\text { Hypotensive Drugs } \\
\text { (Requirements per Day) }\end{array}$} & \multicolumn{2}{|c|}{ Renal Function } \\
\hline & & & $\begin{array}{l}\text { Creatinine } \\
\text { Clearance } \\
\text { (ml/min) }\end{array}$ & $\begin{array}{c}\text { Serum } \\
\text { Creatinine } \\
\text { (mg/100 ml) }\end{array}$ & & & $\begin{array}{l}\text { Creatinine } \\
\text { Clearance } \\
\text { (ml/min) }\end{array}$ & $\begin{array}{c}\text { Serum } \\
\text { Creatinine } \\
(\mathrm{mg} / 100 \mathrm{ml})\end{array}$ \\
\hline \multirow{5}{*}{$\begin{array}{l}1 \\
2 \\
3 \\
4\end{array}$} & \multirow{5}{*}{$\begin{array}{l}177 / 105 \\
160 / 115 \\
183 / 117 \\
163 / 113\end{array}$} & \multirow{5}{*}{$\begin{array}{l}\text { Debrisoquine } 150 \mathrm{mg} \text {, propranolol } \\
320 \mathrm{mg} \text {, pargylin } 20 \mathrm{mg} \\
\text { Debrisoquine } 120 \mathrm{mg} \text { propranolol } \\
360 \mathrm{mg} \text {, bendrofluazide } 10 \mathrm{mg} \\
\text { Debrisoquine } 120 \mathrm{mg} \text {, propranolol } \\
360 \mathrm{mg} \text {, bendrofluazide } 10 \mathrm{mg} \\
\text { Debrisoquine } 150 \mathrm{mg} \text {, } \\
\text { propranolol } 240 \mathrm{mg}\end{array}$} & 26 & $2 \cdot 0$ & & Transplant Removed & & \\
\hline & & & & 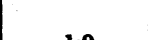 & & Debrisoquine $150 \mathrm{mg}$, diazoxide & & \\
\hline & & & 58 & 1.9 & $155 / 100$ & 150 mg, benaronuaziae 5 mg & 40 & 1.9 \\
\hline & & & 87 & $1 \cdot 0$ & $135 / 88$ & Debrisoquine $40 \mathrm{mg}$ & 103 & $1 \cdot 0$ \\
\hline & & & 148 & 0.7 & $147 / 108$ & Bendrofluazine $10 \mathrm{mg}$ & 171 & 0.7 \\
\hline
\end{tabular}

patient the renal function remained unchanged, but he soon needed very large doses of hypotensive drugs (table IV). In the other two patients who were nephrectomized when transplant function was excellent renal function remained excellent and blood pressure control was achieved with very much smaller doses of hypotensive agents.

\section{Discussion}

There are a number of well-recognized causes of hypertension in renal transplant recipients-namely, acute rejection episodes (Starzl et al., 1963), deterioration of renal function due to chronic rejection (Starzl et al., 1964; Ducrot et al., 1965), and the development of renal artery stenosis (Ducrot et al., 1965).

The results of this study confirm that persisting hypertension in renal transplant recipients may be related to rejection of the kidney as shown by deteriorating renal function or the development of renal artery stenosis, but also the presence of the recipient's own diseased kidneys is an important factor. The significance of the presence of the original kidneys is underlined by the fact that in our non-nephrectomized patients renal function was usually very good in the presnce of hypertension, and further this hypertension was dramatically improved in two patients in whom bilateral nephrectomy was done when the transplant was functioning well. These findings are in agreement with those of Papadimitriou et al. (1969) who recommended bilateral nephrectomy for patients who had persistent hypertension after transplantation.

Other studies of blood pressure after transplantation do not agree with the findings described here, but in none of these studies (Ducrot et al., 1965; Stokes et al., 1970) was differentiation made between hypertensive recipients with or without good function. Stokes et al. (1970) found that hypertension after successful renal transplantation could not be related to the presence or absence of the recipient's own kidneys but there was a correlation between hypertension during dialysis and after transplantation.

Ducrot et al. (1965) stated that blood pressure returned to normal even when the kidneys of the recipient were left in situ. But of the 32 transplants they reported, 15 were in nephrectomized recipients, 11 of the remaining recipients were nephrectomized within seven months after transplantation, and only two patients who had not been nephrectomized had been followed for more than six months at that time.

It must be conceded that the levels of hypertension seen after transplantation are not very severe, but it is nevertheless interesting that some patients in this series remain hypertensive in spite of a normally functioning transplanted kidney. It is possible that after transplantation of this third kidney the blood flow to the recipient's own diseased kidneys is further diminished, and this could result in the release of pressor substances. Of five patients who had "dialysis resistant" hypertension in the nonnephrectomized group, three had hypertension in the presence of excellent transplant function. All four of the patients in the non-nephrectomized group who were subsequently nephrecto- mized had had malignant hypertension before transplantation.

There has been much interest in the subject of hypertension in end-stage renal disease, particularly since anephric patients can now survive for prolonged periods, thus making it possible to study the role of the kidney in the hypertension of terminal renal failure. Merrill et al. (1961) studied four anephric patients and found that hypertension appeared only as a result of excess hydration.

Kolff et al. (1964) extended these findings, and in a study of the effect of bilateral nephrectomy on hypertension in man showed that bilateral nephrectomy did not always facilitate the control of hypertension. Bilateral nephrectomy was performed in 10 of their patients; in six control of blood pressure was easier after this operation, but in the remaining four there was little change. They reported high renin content of kidneys removed from patients whose hypertension was controlled by bilateral nephrectomy.

Some workers studying blood pressure in patients with chronic renal failure treated by intermittent haemodialysis have reported that hypertension may be controlled by dialysis and dietary salt and water restriction alone without recourse to bilateral nephrectomy (Comty et al., 1964) or hypotensive drugs (Craswell et al., 1972). Most dialysis units are unable to reproduce these results. Vertes et al. (1969) described two patterns of response to achievement of dry weight, defined as the weight at which the patient was clinically free of oedema, and hypotension could be transiently induced by further acute weight reduction in 40 patients with end-stage renal disease. Of the 40 patients, 35 remained normotensive without hypotensive therapy as long as dry weight was maintained, but in the other five hypertension persisted in spite of ultrafiltration and sodium restriction. It responded poorly to drug therapy but bilateral nephrectomy resulted in lowering of the pressure. These five patients had high renin levels and Vertes et al. (1969) suggested that plasma renin levels might predict response of blood pressure to dialysis. Wilkinson et al. (1970) reported that three patients in whom bilateral nephrectomy did not result in a lowering of blood pressure had plasma renin levels much lower than their patients whose hypertension did respond to bilateral nephrectomy. Weidmann et al. (1971) reported on 18 patients in terminal renal failure with dialysis and drug resistant hypertension; only one patient in this group did not benefit from nephrectomy and this was the only one in the group whose plasma renin activity was not raised. Plasma renin studies were not performed in our group of patients, but it is interesting to note that Verniory et al. (1972) reported that in terminal renal failure the kidney can secrete renin in response to haemorrhage or other stimuli.

In three nephrectomized patients hypertension at six months heralded progressive decline in renal function with resulting loss of the transplant. It is difficult, however, to explain how four of the 59 nephrectomized recipients had persistent hypertension despite excellent renal function. It is possible that these four had vascular lesions in the transplant capable of producing hypertension but as yet not severe enough to cause impairment of the tests of renal function used in this study. Alternatively 
they could conceivably have an extrarenal cause for the hypertension. It is well known that renin, angiotensin I, and angiotensin II are measurable in the blood of many anephric patients (Medina et al., 1972).

From the data presented here it would seem reasonable to conclude that the presence of diseased kidneys alone is sufficient to sustain hypertension in some transplant patients in the presence of a normally functioning transplant. This would suggest that the normal kidney does not produce a depressor substance but the diseased kidneys in spite of their minimal blood flow are still able to produce a pressor effect.

It is of interest that the mean renal function in all our nonnephrectomized recipients was better than in the nephrectomized patients compared six months after transplantation. This could possibly be related to improvements in technique, as the patients who retained their kidneys were transplanted more recently.

Finally, in non-nephrectomized recipients, if hypertension persists despite good transplant function, if rejection and renal artery stenosis are excluded, bilateral nephrectomy may be indicated. In the four patients in this series who were bilaterally nephrectomized for hypertension after transplantation (table IV), hypertension became significantly easier to control in two, both of whom had good renal function. In the other two patients hypertension was ameliorated only temporarily by removal of their original kidneys. Five months after the bilateral nephrectomy irreversible decline in transplant function occurred in one patient who had become severely hypertensive again. Histology of this transplant showed severe obliterative arterial lesions. As none of the transplants in the other three patients were biopsied the possible contribution of vascular lesions in the kidney to their hypertension remains conjectural.

I would like to thank Professor W. S. Peart and Dr. B. Hulme for their helpful comments and for allowing me to study patients under their care, Mr. K. Owen, Mr. J. R. Kenyon, and Mr. M. E. Snell who performed the surgery, and Miss Aviva Petrie of the London School of Hygiene and Tropical Medicine for the statistics.

\section{References}

Comty, C., Rottka, H., and Shaldon, S. (1964). Proceedings of the European Dialysis and Transplant Association, 1, 209.

Craswell, P. W., et al. (1972). Proceedings of the European Dialysis and Transplant Association. In press.

Ducrot, H., et al. (1965). Pathologie et Biologie, 13, 1070.

Kolff, W. J., Nakamoto, S., Poutasse, E. F., Strafion, R. A., and Figueroa, J. E. (1964). Circulation 29-30, Suppl., 23.

Medina, A., et al. (1972). British Medical fournal, 4, 694

Merrill, J. P., Giordano, C., and Heetderks, D. R. (1961). American fournal of Medicine, 31, 931 .

Papadimitriou, M., Chisholm, G. D., and Shackman, R. (1960). Lancet, 1, 902.

Peart, W. S. (1970). In Biology and Surgery of Tissue Transplantation, ed. J. Maxwell Anderson, p. 233. Edinburgh, Blackwell Scientific.

Starlz, T. E., Marchioro, T. L., and Waddell, W. R. (1963). Surgery, Gynecology and Obstetrics, 117, 385.

Starlz, T. E., et al. (1964). Annals of Internal Medicine, 61, 470.

Stokes, G. S., Mani, M. K., and Stewart, J. H. (1970). British Medical fournal, 3, 126

Verniory, A., et al. (1972). Clinical Science, 42, 685.

Vertes, V., Cangiano, J. L., Berman, L. B., and Gould, A. (1969). New England Fournal of Medicine, 280, 978 .

Weidmann, P., Maxwell, M. H., Lupu, A. N., Lewin, A. J., and Massry, S. G. (1971). Nero England fournal of Medicine, 285, 757 .

Wilkinson, R., et al. (1970). Quarterly fournal of Medicine, 39, 377.

\title{
Immunological Function in Dystrophia Myotonica
}

\author{
D. I. GROVE, S. J. O’CALLAGHAN, T. O. BURSTON, I. J. FORBES
}

British Medical fournal, 1973, 3, 81-83

\section{Summary}

Humoral and cellular immunity have been investigated in 15 patients with dystrophia myotonica. No abnormalities in total serum levels of the five major immunoglobulin classes were found but there was a rise in the mean serum level of $\beta_{1} A$ complement. Altogether, $54 \%$ of patients failed to make antibody to tetanus toxoid as compared with $1 \%$ of controls: $13 \%$ of patients failed to make antibody to Salmonella typhi $H$ antigen as compared with no failure of this function in control subjects. There was a reduced uptake of tritiated thymidine by whole blood lymphocyte cultures spontaneously, while in the presence of phytohaemagglutinin (PHA) and both autologous and fetal calf serum the uptake was normal. It is suggested that there may be a wider derangement of immunological function in dystrophia myotonica than previously thought.

\footnotetext{
University of Adelaide, Department of Medicine, The Queen Elizabeth Hospital, Woodville, South Australia, 5011

D. I. GROVE, M.B., M.R.A.C.P., National Health and Medical Research Council Postgraduate Research Scholar

S. J. O'CALLOGHAN, Medical Student

S. J. O'CALLOGHAN, Medical Student

T. O. BURSTON, B.sc., Assistant Biochemist, Department of Clinical Chemistry
}

\section{Introduction}

Reduced serum levels of gammaglobulin have been found in many patients with dystrophia myotonica by some workers (Lowenthal and van Sande, 1956; Kuhn and Weicker, 1957) but not by others (Oppenheimer and Milhorat, 1961). These reduced levels were observed to be associated with a reduction in the half life of ${ }^{181}$ I-labelled gammaglobulin (Zinneman and Rotstein, 1956). With the delineation of the various immunoglobulin classes it was found that there were reduced serum levels and increased catabolism of immunoglobulin (Ig) G (Wochner et al., 1966), though a more recent report suggested that serum levels of IgM may also be reduced (Bundey et al., 1970). These abnormalities prompted a more comprehensive investigation of immunological function in this disease.

\section{Patients and Methods}

Altogether, 15 patients were studied, including two pairs of siblings and one mother and daughter. Each patient had characteristic clinical features and showed the classical electromyographic changes of dystrophia myotonica. It is difficult to be certain of the duration of clinical symptoms, but the average was 10 years and ranged from five to 16 years. There were eight men and seven women, with ages ranging between 30 and 71 years (see table II). Two patients were in institutions, the rest living at home. Two patients were receiving digoxin and diuretics for congestive cardiac failure and one was receiving bronchodilators for chronic bronchitis. One patient suffered with rheumatoid arthritis but was receiving no therapy, while 